\title{
MARKETING EMOCIONAL COMO ESTRATÉGIA DE FIDELIZAÇÃO
}

\author{
Leticia Araujo da Silveira ${ }^{1}$ \\ Professor Orientador: Eduardo de Freitas Vicente ${ }^{2}$
}

\section{RESUMO}

Este artigo fundamenta-se em uma pesquisa descritiva com o propósito de contribuir com o estudo de temáticas de marketing e suas ferramentas, tendo como objetivo principal avaliar a eficácia do marketing emocional como estratégia de fidelização de clientes. Para isso, apresentou-se o conceito de marketing emocional e fidelização de clientes, seguido de uma análise da relação desses conceitos, sendo cada uma dessas etapas objetivos secundários do trabalho. Por fim, buscou-se pontos em comum entre os resultados da pesquisa bibliográfica e os dados resultantes da pesquisa de campo. Os resultados comprovaram os benefícios da conexão emocional na retenção de clientes, sendo esta mais efetiva do que concorrer por produto ou preço.

Palavras-chave: marketing. marketing emocional. fidelização de clientes.

\section{ABSTRACT}

This article is based on descriptive research with the purpose of contributing to the study of marketing themes and their tools, with the main objective of evaluating the effectiveness of emotional marketing as a customer loyalty strategy. For this, the concept of emotional marketing and customer loyalty was presented, followed by an analysis of the correlation bettween these concepts, each of these stages being secondary objectives of this work. Finally, we searched for points in common between the results of the bibliographic research and the data resulting from the online survey. The results proved the benefits of emotional connection in retaining customers, being more effective than competing for product or price.

Keywords: marketing. emotional marketing. customer loyalty.

\section{INTRODUÇÃO}

Embora seja uma tendência de mercado apostar em estratégias de marketing emocional, pode haver receio por parte das empresas em investir em ações dessa natureza. Há ainda, a percepção por parte de empresas menores de que esta é uma estratégia muito custosa, aplicável somente para empresas de médio e grande porte que tenham um grande orçamento de marketing. Os investimentos em marketing são baseados em projeções de retorno sobre investimento (ROI), e quando se trata de marketing emocional, torna-se mais complexo mensurar o impacto nos resultados da empresa. É sabido que um sentimento positivo por uma

\footnotetext{
${ }^{1}$ Pós-graduanda do MBA em Comunicação e Marketing pela Universidade Cruzeiro do Sul - UNICSUL

2 Professor orientador do curso MBA em Comunicação e Marketing da Universidade Cruzeiro do Sul UNICSUL
} 
marca pode contribuir para sua consolidação no mercado, mas qual é a eficácia do marketing emocional como estratégia de fidelização de clientes?

O presente estudo visa avaliar dados relacionados ao tema para a validação ou invalidação da hipótese de que o marketing emocional impacta diretamente na fidelização de clientes, contribuindo para que empresas e profissionais de marketing possam tomar decisões com base em dados. A pesquisa tem como objetivo principal avaliar a eficácia do marketing emocional como estratégia de fidelização. Os objetivos secundários são, respectivamente: conceituar marketing emocional, conceituar fidelização de clientes e analisar a relação entre a conexão emocional e a fidelização de clientes.

Seguindo a linha do estudo de temáticas de marketing e suas ferramentas, a motivação partiu da oportunidade de aumentar o acervo teórico sobre o tema, contribuindo com o estudo nessa área e para que estudantes e profissionais tenham dados que permitam justificar de forma mais assertiva os investimentos em marketing emocional.

Foi realizada uma pesquisa descritiva, dividida em duas fases. A primeira fase se deu meio de pesquisa bibliográfica. A segunda fase foi prática, por meio de um questionário online com o objetivo de validar a eficácia do marketing emocional na fidelização. A pesquisa realizada teve caráter quantitativo, afim de possibilitar uma análise estatística. O questionário online foi compartilhado em Redes Sociais e por aplicativos de mensagens instantâneas, sendo colhidas 156 respostas no período de 08/05/2020 a 16/05/2020.

O presente trabalho está dividido em quatro capítulos, sendo o primeiro a introdução, que apresenta tema, justificativa, problema e objetivos geral e secundários do trabalho. $\mathrm{O}$ segundo capítulo traz a fundamentação teórica, apresentando as principais ideias dos autores sobre o tema, dividindo-se em tópicos que apresentam, respectivamente: evolução do marketing 1.0 ao marketing 4.0, conceito de marketing emocional, conceito de fidelização de clientes, e por fim, a análise da relação entre conexão emocional e fidelização de clientes. O terceiro capítulo traz a análise dos resultados obtidos na pesquisa de campo. Por fim, no quarto capítulo, temos as considerações finais que buscam analisar, interpretar e concluir se o problema da pesquisa foi respondido e se os objetivos foram alcançados.

\section{FUNDAMENTAÇÃO TEÓRICA}

\subsection{Do marketing 1.0 ao 4.0}

Segundo Kotler (2012, p. 3), “o marketing envolve a identificação e a satisfação das necessidades humanas e sociais". Seu papel é atender a demanda do mercado por meio de produtos ou serviços numa troca de valor. Na evolução do marketing tradicional (1.0) para o 
marketing digital (4.0), caminhamos de uma visão com foco no produto (que teve como força habilitadora a revolução industrial) para uma visão voltada para a colaboração (que tem como força habilitadora a digitalização), como podemos ver no Quadro 1.

Quadro 1- Do Marketing 1.0 ao Marketing 4.0

\begin{tabular}{|c|c|c|c|c|}
\hline & Marketing 1.0 & Marketing 2.0 & Marketing 3.0 & Marketing 4.0 \\
\hline Foco & Prodiuto & Clientes & Valores & Colaboraçāo \\
\hline Objetivo & Produto de vendas & Satisfazer e fizelizar o cliente & $\begin{array}{l}\text { Fazer do mundo um lugar } \\
\text { melhor }\end{array}$ & Envolver o cliente \\
\hline $\begin{array}{c}\text { Como as empresas veem o } \\
\text { mercado }\end{array}$ & $\begin{array}{l}\text { Comprador massivo com } \\
\text { necessidades fisicas }\end{array}$ & $\begin{array}{l}\text { Consumidor inteligente com } \\
\text { mente e coraçâo }\end{array}$ & $\begin{array}{l}\text { Ser humano completo com } \\
\text { mente, coraçâo e espirito }\end{array}$ & Ser humano social \\
\hline Forças habilitadoras & Revoluçầo Industrial & Informação tecnológica & Tecnologia New Waves & Digitalização \\
\hline $\begin{array}{c}\text { Conceitos-chave do } \\
\text { marketing }\end{array}$ & Desenvolvimento de produto & Diferenciação & Corporativo, visaao e valores & Colaboração \\
\hline $\begin{array}{c}\text { Gerentes de marketing da } \\
\text { empresa }\end{array}$ & Especificaçâo do produto & $\begin{array}{l}\text { Posicionamento corporativo } \\
\text { e de produto }\end{array}$ & Valores & Gerar engajamentc \\
\hline Propostas de valor & Funcional & Funcional e emocional & $\begin{array}{c}\text { Funcional, emocional e } \\
\text { espiritual }\end{array}$ & Social \\
\hline $\begin{array}{l}\text { Interação com o } \\
\text { consumidor }\end{array}$ & $\begin{array}{l}\text { Transaçōes de um para } \\
\text { muitos }\end{array}$ & Relacionamento um para um & $\begin{array}{l}\text { Colaboraçâo de muitos para } \\
\text { muitos }\end{array}$ & Hibrido \\
\hline
\end{tabular}

Fonte: Comunidade Sebrae (c2019)

O marketing 2.0 mudou o foco para o consumidor, que se tornou mais exigente e impulsionou as marcas a buscarem a diferenciação. O objetivo passou a ser satisfazer e fidelizar o cliente (que passa a ser visto como um ser inteligente com mente e coração), agregando o fator emocional à proposta de valor e trazendo o relacionamento de um para um (COMUNIDADE SEBRAE, c2019).

Evoluindo para o marketing 3.0, passa-se a enxergar o consumidor como um ser completo (corpo, alma e espírito). Não basta um produto ou serviço de qualidade, o consumidor "exige também atendimento diferenciado, valores condizentes com os seus, compromisso com causas sociais e propósito de marca" (COMUNIDADE SEBRAE, c2019). Pode-se notar o quanto o consumidor busca uma relação que vai além da funcionalidade do produto ou do serviço por si só, exigindo que a marca apresente também seus valores e visão de mundo.

O marketing 4.0 é um desdobramento do marketing 3.0, combinando a interação online e off-line entre empresas e consumidores e reconhecendo os papéis do marketing tradicional e do digital na busca de engajamento e defesa de marca (KOTLER, KARTAJAYA e SETIWAN, 2017). Fica claro que não se trata de substituir o tradicional pelo digital, mas sim que eles devem coexistir na jornada em busca da fidelização.

Acompanhando a evolução do marketing até aqui, podemos afirmar que enxergar o ser humano como um ser completo permitiu uma aproximação das empresas com o consumidor ao exigir que as marcas se posicionem também de forma completa (produto, visão, 
valores e a forma como contribui com a sociedade), humanizando as empresas. A digitalização ampliou o alcance e trouxe mais interação, pois quando uma marca se comunica com o cliente, está abrindo espaço para que ele responda e que toda uma rede interaja sobre o tema. Constatase que, quando a identificação com esse posicionamento acontece, o consumidor está conectado à marca nos três níveis (mental, emocional e espiritual), e esse envolvimento traz engajamento e colaboração, impulsionando que o consumidor compartilhe suas experiências e emoções em relação a essa marca.

\subsection{Marketing emocional}

Quando perguntamos a alguém porque ama ou odeia uma marca, a resposta geralmente vem acompanhada de uma história que descreve como a pessoa se sentiu diante daquele cenário. O ser humano é um ser emocional, e a preferência por uma marca carrega sentimentos e geralmente, boas memórias. Marketing emocional inclui carinho em sua definição, sendo este a ponte entre satisfação e fidelidade e a forma de demonstrar ao cliente que a marca realmente se importa com ele (ROBINETTE, BRAND e LENZ, 2002).

O marketing emocional busca uma conexão com os clientes por meio de sentimentos e, embora seja uma ferramenta de marketing, necessita do envolvimento de todas as áreas da empresa. Robinette, Brand e Lenz (2002, p. 4) definem marketing emocional como "a busca em que a empresa deve se envolver como um todo, adquirindo conexão sustentável com os consumidores".

Para os autores, há cinco fatores que devem ser levados em consideração para aplicar o marketing emocional: Dinheiro, Produto, Patrimônio, Experiência e Energia. Esses elementos fazem parte da estrutura motivacional Estrela do Valor, criada pela Hallmark a partir de um levantamento com milhares de consumidores com o objetivo de compreender o que seus clientes valorizavam.

Dinheiro e Produto são as pontas racionais da estrela, fatores movidos pela lógica no momento de decisão da compra, quando o consumidor analisa o preço e atributos do produto. Embora sejam fatores fáceis de copiar, não podem ser negligenciados. "Mesmo o considerável poder da emoção não conseguirá sobrepujar um produto obviamente inferior com um preço não razoável." (ROBINETTE, BRAND e LENZ, 2002, grifo do autor). É importante que a empresa invista em um bom produto, buscando aplicar diferenciais inovadores. Contudo, os autores alertam que "a dependência continuada desses impulsionadores de valor apresenta o risco de transformar o produto em uma commodity" (ROBINETTE; BRAND; LENZ, 2002, p.23). 
Os outros três impulsionadores de valor apresentados pelos autores no modelo são Patrimônio, Experiência e Energia, as pontas emocionais da estrela. Patrimônio é a confiança que o consumidor tem na marca, composta pela sinergia entre a identidade da marca (o que a empresa busca ser) e pela imagem da marca (como o consumidor percebe e se identifica com a marca). Já a experiência é composta de todos os pontos de contato da empresa com o cliente, tendo como ponto central o uso do próprio produto ou serviço. Por fim, energia se refere a tempo, ou seja, "tornar um produto ou serviço mais acessível, mais fácil ou mais rápido. " (ROBINETTE; BRAND; LENZ, 2002, p.78).

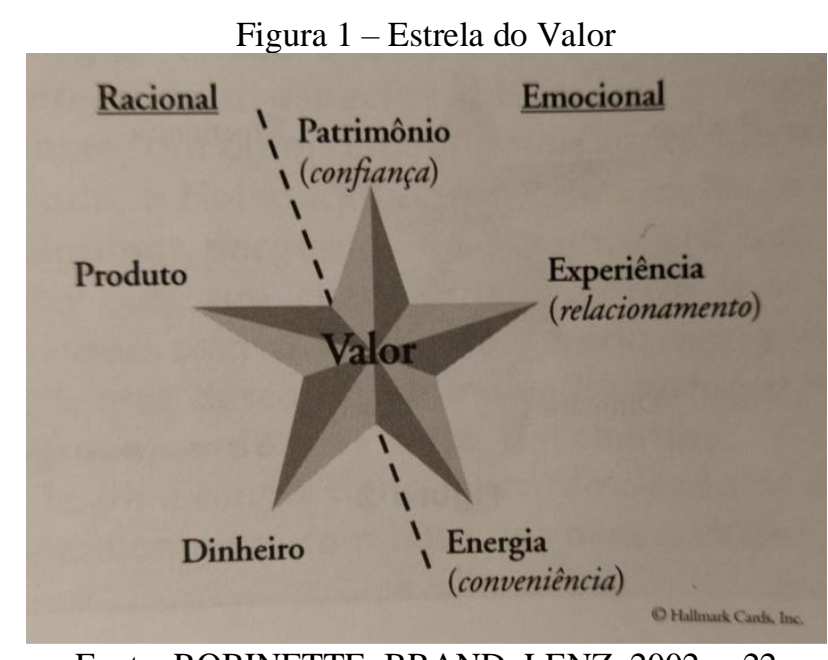

Fonte: ROBINETTE; BRAND; LENZ, 2002, p.22

As pontas emocionais da estrela fazem oscilar as decisões de compra, mas todo consumidor busca uma relação custo-benefício satisfatória em primeiro lugar. Robinette, Brand e Lenz (2002, p.90, grifo do autor) ressaltam esse ponto ao afirmar que "Embora Patrimônio da Marca, Experiência e Energia ajudem uma empresa a vencer, o Produto e o Dinheiro são absolutamente prioritários para iniciar o jogo". Dessa forma, conclui-se que um preço atrativo e um produto de qualidade são essenciais nessa relação, sendo ponto de entrada de uma empresa no mercado.

\subsection{Fidelização de clientes}

A fidelização de clientes resulta de uma série de interações com a marca, representando o último estágio de uma jornada. Segundo Kotler, Kartajaya e Setiwan (2017) o caminho do consumidor passa por fases chamada de 5 As:

a) Assimilação: Para Kotler, Kartajaya e Setiwan (2017), assimilação é o momento em que o consumidor é exposto passivamente a uma grande lista de marcas, algumas delas podendo já serem conhecidas por meio de experiências passadas, publicidade ou recomendação. 
b) Atração: Kotler, Kartajaya e Setiwan (2017) afirmam que a fase atração é o momento em que o consumidor é atraído para uma lista menor de marcas após processar todas as mensagens a que foi exposto.

c) Arguição: Segundo Kotler, Kartajaya e Setiwan (2017), nesta fase o consumidor parte para a pesquisa sobre as marcas pelas quais foi atraído, partindo de uma fase individual para uma fase social da jornada, chamada de Arguição. É na fase de arguição que o consumidor se conecta com comentários, avaliações e recomendações. Se convencido pelas informações recebidas nessa fase, o consumidor passa para a próxima fase.

d) Ação: Kotler, Kartajaya e Setiwan (2017) enfatizam que as ações desejadas não se limitam a ações de compra, e que é importante que as marcas proporcionem experiências positivas memoráveis após a compra.

e) Apologia: Kotler, Kartajaya e Setiwan (2017) explicam que essa é a fase em que o consumidor pode desenvolver uma forte sensação de fidelidade que se reflete em retenção, recompra e defesa de marca, passando a falar bem da marca para pares, amigos e familiares.

Figura 2-Caminho do consumidor ao longo os 5 As

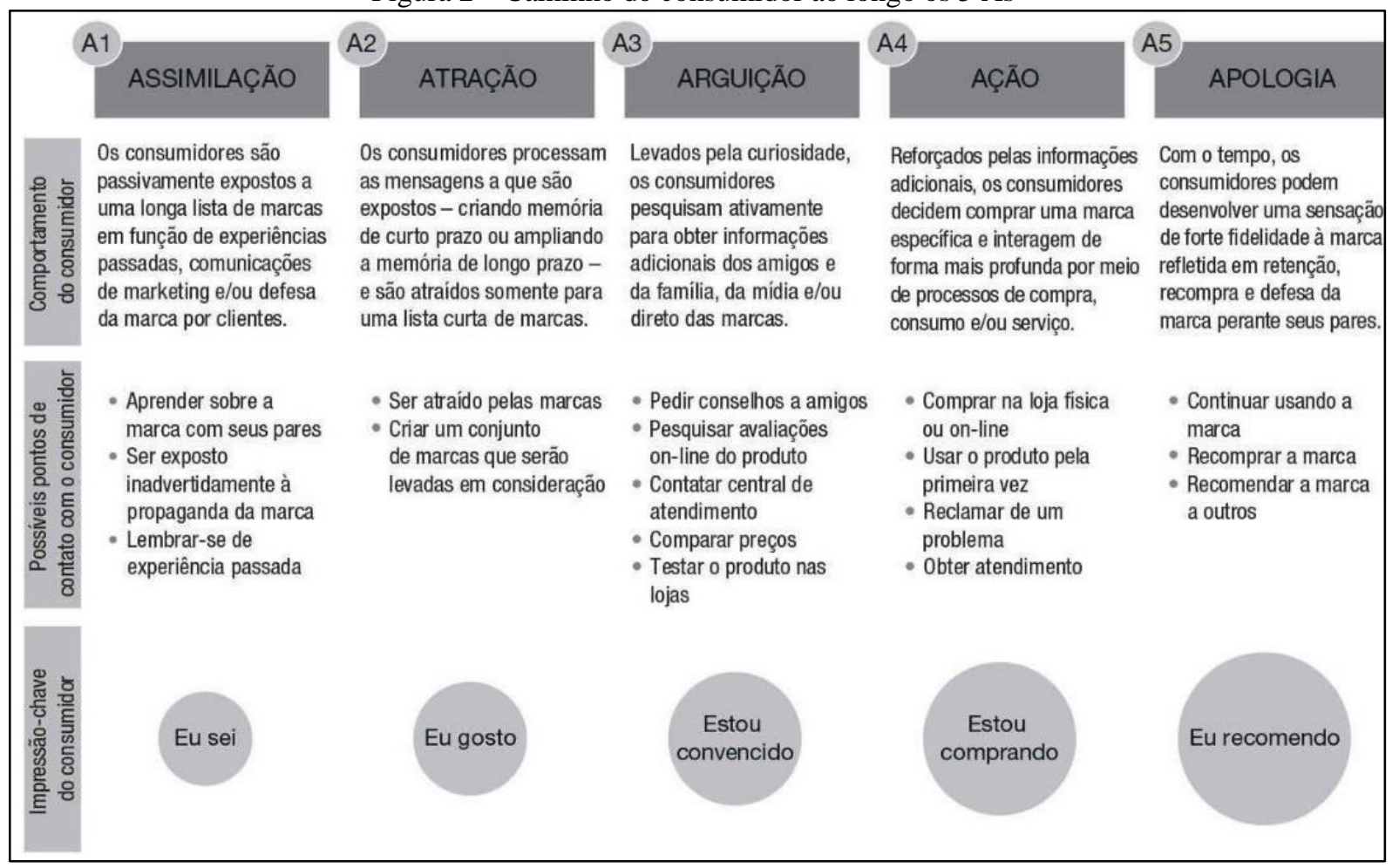

Fonte: KOTLER, P., KARTAJAYA, H., SETIWAN (2017)

De acordo com Marques (2006, p. 61), a verdadeira forma de fidelidade é conquistar um lugar no coração dos clientes (heart share) ao tratar as pessoas com carinho sincero e respeito. Kotler, Kartajaya e Setiwan (2017, p.108) afirmam que "um grande número de clientes encantados se reflete em um alto índice de fidelidade" e que "a fidelidade em si tem sido 
redefinida como a disposição do cliente para recomendar uma marca específica". Dessa forma, assimilamos que é possível e recomendável que as marcas busquem proporcionar uma experiência positiva desde a primeira fase do caminho do consumidor. Nota-se também a importância de uma boa relação pós-venda, que, por meio de clientes encantados que defendem a marca, geram avaliações e conteúdo positivo que podem "puxar" novos consumidores da fase de atração para a fase de ação.

\subsection{Relação entre conexão emocional e fidelização de clientes}

É possível uma empresa conseguir replicar características de embalagem, preço, funcionalidade e qualidade, ainda que leve um certo tempo. Mas quando entramos no campo de humanização da marca, trazendo valores, cultura e jeito de se relacionar com o cliente, ocorre uma diferenciação. Ao conquistar o coração do cliente deixando-o altamente satisfeito ou encantado, este tende a permanecer fiel por mais tempo, além de falar bem da empresa e de seus produtos e/ou serviços (KOTLER, 2012).

Uma conhecida forma de gerar conexão emocional são as campanhas com histórias marcantes, comerciais que trazem os mais diversos sentimentos, conectando-se com o consumidor. "Se uma marca atinge o ponto certo com campanhas ricas em coração e autenticidade, os consumidores vão mergulhar fundo"3 (FORBES, 2019, tradução nossa). Ocorre que marcas que conseguem construir uma memória afetiva, certamente tem um lugar especial no coração do consumidor, podendo fazer até parte da tradição de uma família.

Segundo Robinette, Brand e Lenz (2002, p.10), o ser humano tem necessidade de pertencer e de se sentir ligado a outros. Seguindo esse pensamento, vemos que marcas que defendem uma causa tem o poder de gerar essa ligação emocional por meio de um senso de comunidade. O Nubank, banco digital, por exemplo, consolidou-se no mercado com o posicionamento de oferecer um produto que fosse de encontro às necessidades dos clientes e contra as burocracias dos bancos tradicionais. A empresa também se posiciona sobre seu premiado modelo de atendimento, chamada WOW, ao afirmar que "mais do que resolver problemas de forma rápida, nossos Xpeers ${ }^{4}$ têm como missão encantar as pessoas e dar a elas o melhor atendimento possível - eficiente, humano e atencioso" (BLOG NUBANK, 2019). Para o consumidor, "vestir" a marca significa abraçar a causa em que acreditam e se reconhecer nessa tribo, é um manifesto.

\footnotetext{
${ }^{3}$ If a brand strikes the right chord with campaigns rich in heart and authenticity, consumers will jump on board for the long haul.

${ }^{4}$ Xpeers é como são chamados os atendentes do Nubank
} 
Com o avanço da inteligência artificial, as marcas têm buscado humanizar chatbots, assistentes virtuais e embaixadores de marca digitais. Companheiros cibernéticos como Alexa, Cortana, Siri e Google Assistente são aprimorados constantemente para tornarem-se amigos, aliados, e agregados à família (FORBES, 2020). A humanização da inteligência artificial tem um papel importante na relação da marca com o consumidor ao permitir que durante a interação com a máquina as pessoas possam ter a mesma sensação de estar com uma pessoa de confiança. Ao implementar características como expressões faciais, linguagem próxima e personalidade, é possível criar laços emocionais com "máquinas". "Quando as máquinas parecem, soam, agem e reagem como humanos, a conexão emocional e todos os seus benefícios estão sobre a mesa. "5 (FORBES, tradução nossa).

"Simplificando, conexão emocional é considerada mais efetiva do que competir por produto ou preço. É o mais alto nível de experiência do cliente que impacta diretamente no aumento de renovação e retenção. "6 (FORBES, 2020, tradução nossa). Robinette, Brand e Lenz (2002) comparam o marketing emocional com o marketing comum nesse quesito e afirmam que, embora o marketing comum possa modificar o sentimento de um consumidor, o marketing emocional consegue ir além e abre as portas para um relacionamento de longo prazo.

O marketing comum pode modificar os sentimentos de uma pessoa sobre uma empresa. Mas o marketing emocional impele as pessoas a agir com base nesses sentimentos - e dá lhes uma razão para irem além de uma simples compra e chegarem à fidelidade duradoura. (ROBINETTE, BRAND e LENZ, 2002, p.8).

Ao analisar os conceitos de marketing emocional e fidelidade apresentados, nota-se a relação direta entre os fatores no processo de retenção de clientes e defesa de marca.

\section{DISCUSSÃO/ANÁLISES DOS RESULTADOS}

No segundo capítulo deste artigo acompanhamos a evolução do marketing 1.0 ao 4.0, conceituamos marketing emocional e fidelização de clientes, e por fim, analisamos a relação entre conexão emocional e fidelização de clientes. Neste capítulo, conforme previsto na metodologia, buscamos por meio de uma análise empírica levantar o comportamento dos consumidores em relação a suas marcas preferidas.

\footnotetext{
${ }^{5}$ When the "machines" look, sound, act and react like humans, emotional connection and all its benefits are on the table.

${ }^{6}$ Quite simply, emotional connection is considerably more effective than competing on product or price. It's the highest level of customer experience that directly impacts revenue growth and retention.
} 
A pesquisa foi realizada com o fim de validar a hipótese da eficácia do marketing emocional na fidelização de clientes por meio de perguntas elaboradas pela autora de acordo com o tema proposto e embasamento teórico.

Para a pergunta "Você tem uma marca preferida?", dos 156 respondentes, 62\% informaram ter uma marca preferida, conforme Gráfico 1. Destes 97 que tem uma marca preferida, $67 \%$ consideram ter conexão/vínculo emocional com a marca em questão, conforme o Gráfico 2.

Gráfico 1- Quantidade de pessoas que têm ou não uma marca preferida

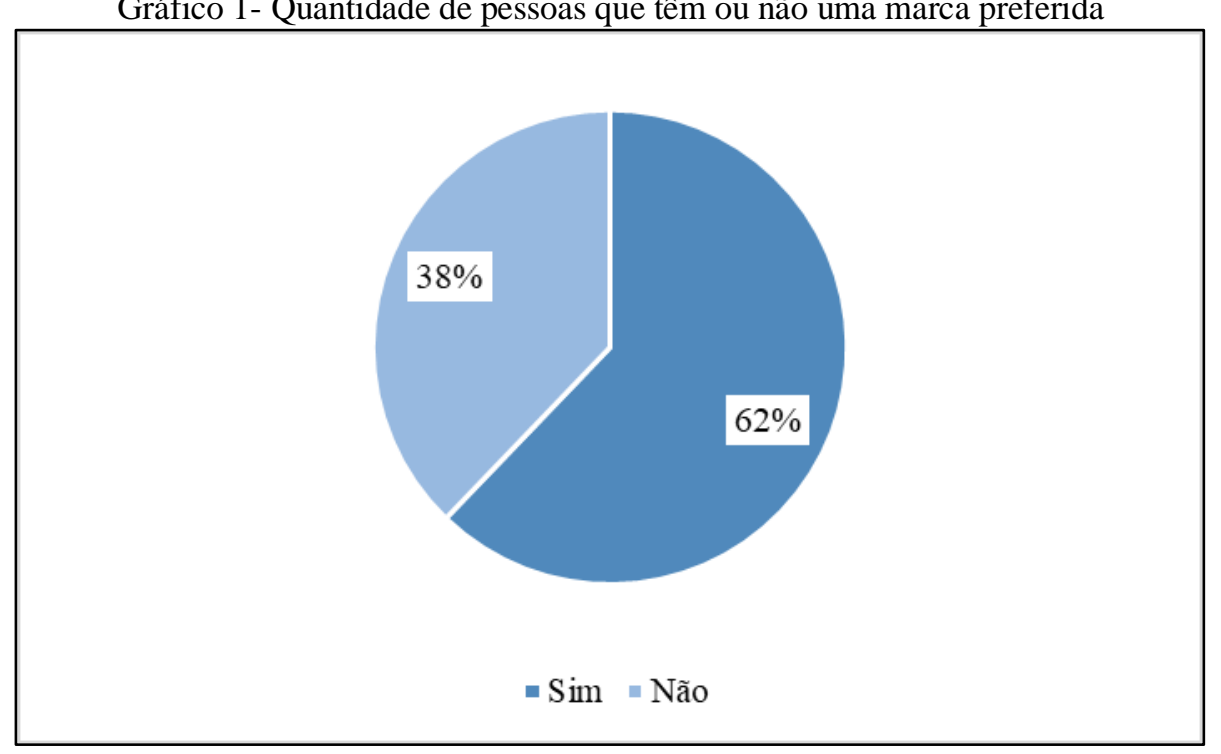

Fonte: A autora

Gráfico 2 - Quantidade de pessoas que consideram ou não ter conexão emocional com a marca preferida

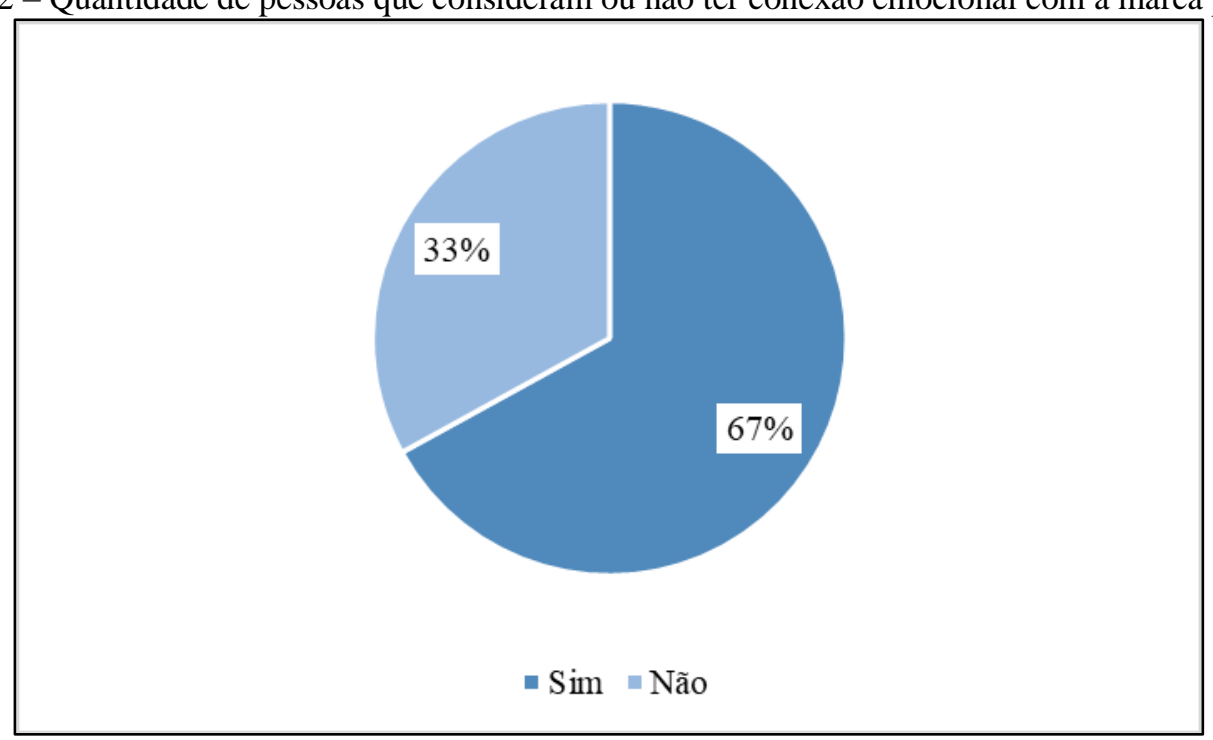

Fonte: A autora

Quanto aos fatores responsáveis pela conexão emocional com a marca preferida, os respondentes poderiam marcar mais de uma opção. Como mostra o gráfico 3 , os três fatores mais citados foram "Memória afetiva", indicado por 54\% dos respondentes, "campanhas com 
histórias marcantes", indicado por 38\% e "atendimento", indicado por $34 \%$, mostrando que tanto estratégias pré-venda como pós-venda podem envolver o cliente. Defender uma causa com a qual o consumidor se identifica foi citada por $28 \%$ dos respondentes, ficando em quarto lugar. "Produto" aparece em quinto lugar, com 11\%.

Gráfico 3 - Que fator(es) é(são) responsável(is) pela conexão/vínculo emocional que você tem por sua marca preferida?

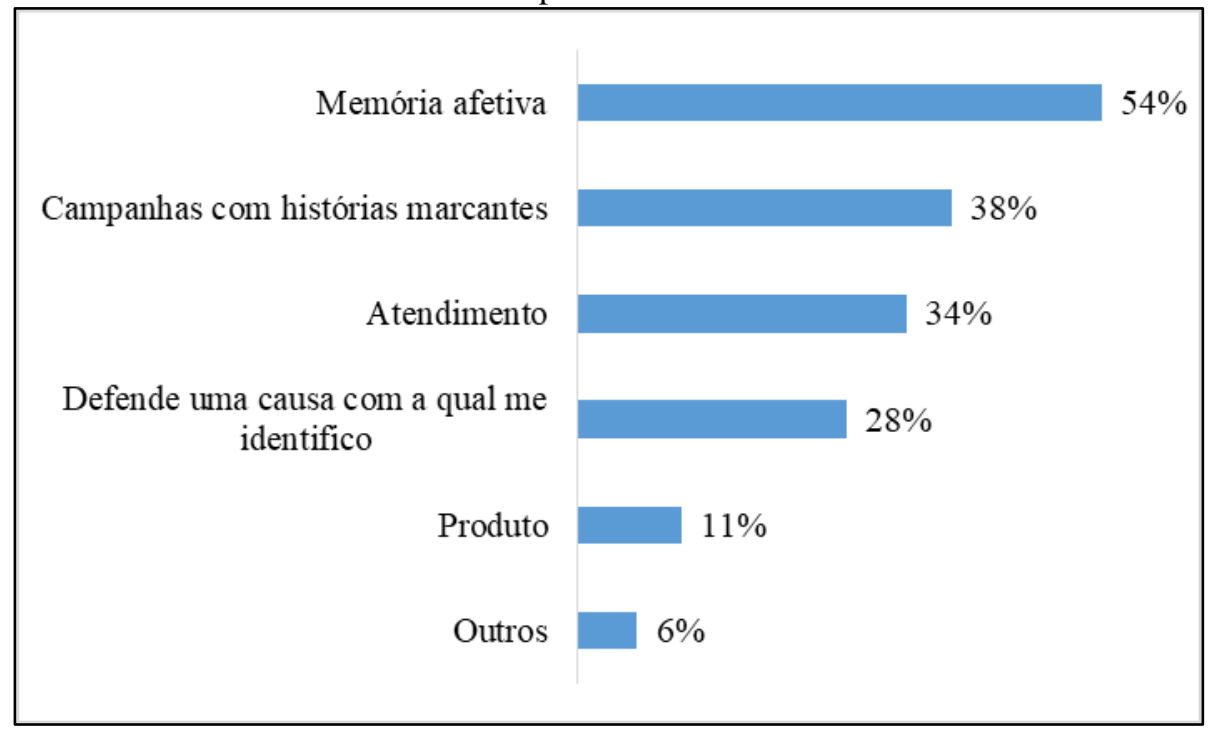

Fonte: A autora

O Gráfico 4 mostra que a porcentagem de consumidores que afirmou já ter falado bem da marca para amigos, familiares ou em redes sociais é maior nos clientes que tem conexão emocional com a marca, sendo de 94\%. Para os consumidores que afirmam não ter conexão emocional, esse número cai para $84 \%$.

Gráfico 4 - Já falou bem da sua marca preferida publicamente (para amigos, familiares ou em redes sociais)?

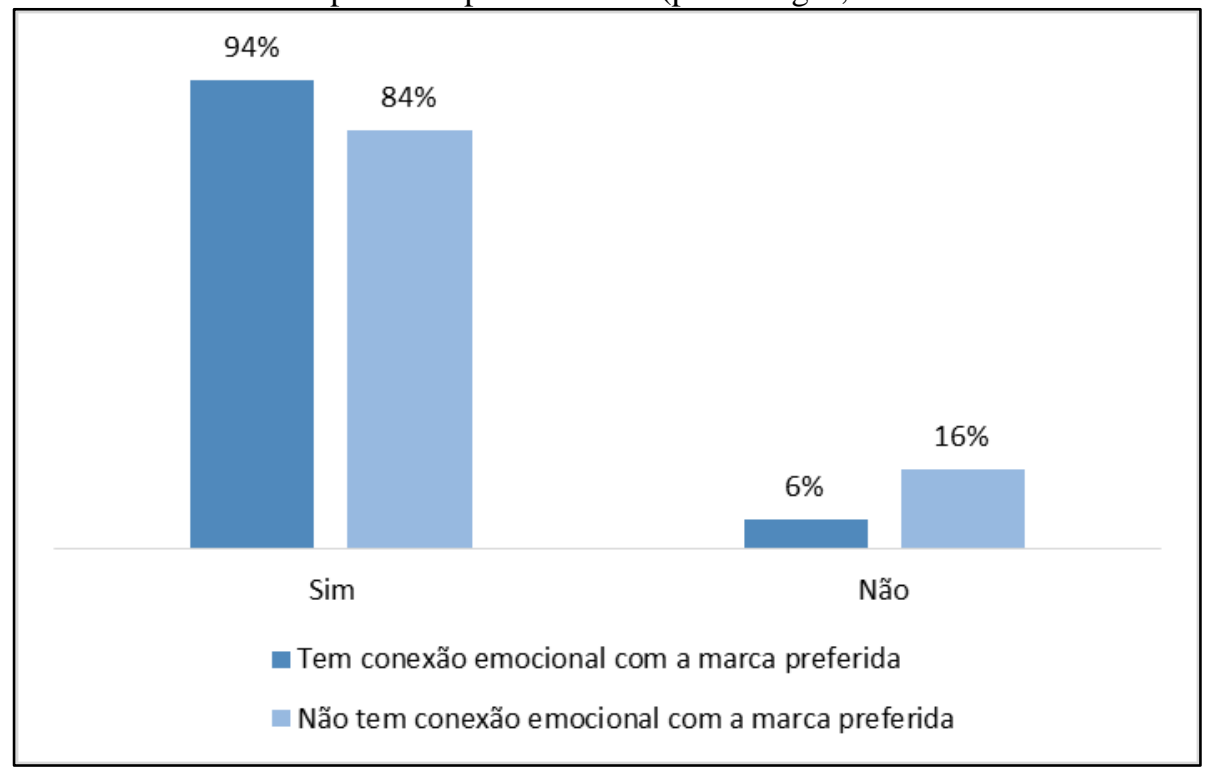

Fonte: A autora 
$59 \%$ dos respondentes que declararam não ter vínculo emocional com a marca preferida, afirmaram dar preferência a marca mesmo se encontrarem outro produto/serviço similar por um preço menor. Para os que declararam ter vínculo emocional, esse número sobe para $78 \%$, como mostra o Gráfico 5.

Gráfico 5 - Você sempre opta por sua marca preferida, mesmo quando encontra um produto/serviço similar por um preço menor?

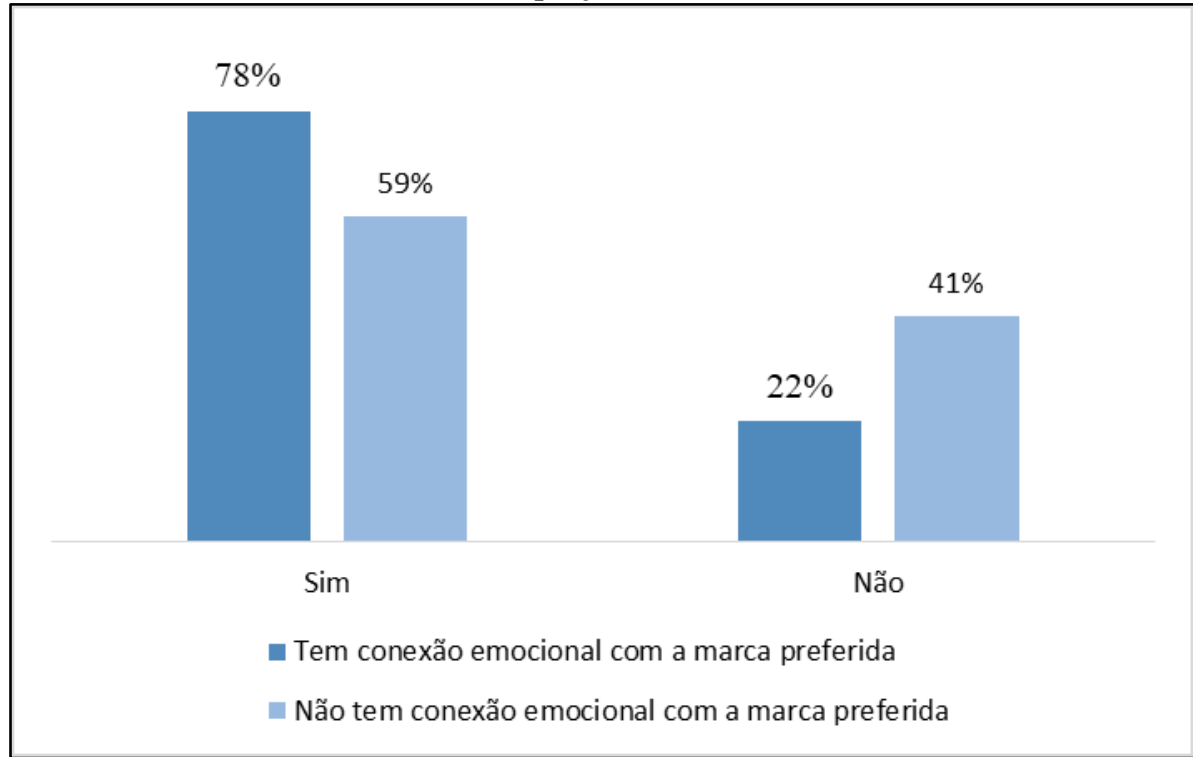

Fonte: A autora

75\% dos respondentes que declararam não ter conexão emocional com a marca preferida afirmam ter predisposição a comprar novos produtos lançados pela marca. Dos que declararam possuir conexão emocional com sua marca preferida, esse número sobe para 91\%, mostrando uma maior propensão a experimentar lançamentos.

Gráfico 6 - Tem predisposição a comprar novos produtos lançados por sua marca preferida?

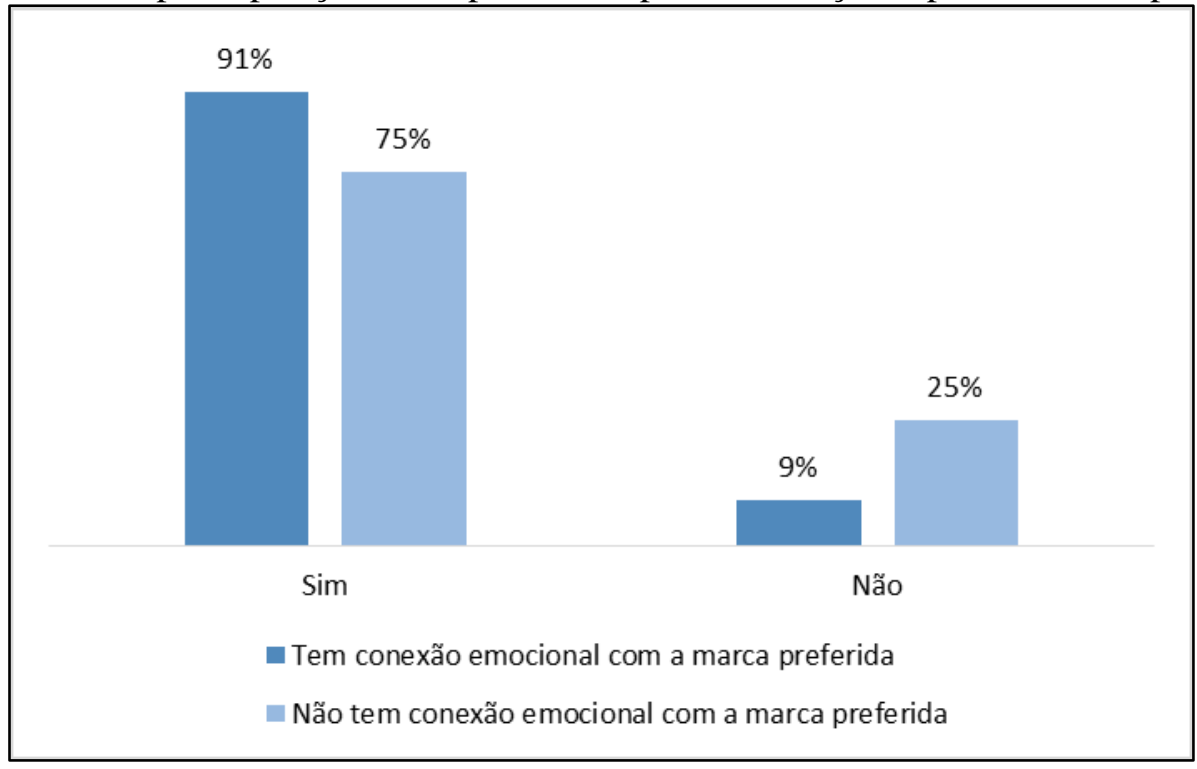

Fonte: A Autora 


\section{CONSIDERAÇÕES FINAIS}

A presente pesquisa científica abordou a eficácia do marketing emocional como estratégia de fidelização de clientes. Primeiramente foi realizado um levantamento bibliográfico, com o intuito de conceituar marketing emocional, conceituar fidelização de clientes, e analisar a relação entre conexão emocional e fidelização de clientes, objetivos que foram atingidos no segundo capítulo deste trabalho.

Podemos dizer que o marketing emocional é uma estratégia voltada para a experiência do cliente, uma relação de carinho que deve nortear toda a companhia, não se restringindo apenas ao time marketing. Sua aplicação contempla elementos racionais (Dinheiro e Produto) e emocionais (Patrimônio, Experiência e Energia). É contemplado em diferentes fases da jornada do cliente e em diferentes contextos, como em campanhas publicitárias, no atendimento ao cliente e durante a utilização do produto por meio de personalização, criando uma relação de amizade entre marca e consumidor por meio da humanização.

Em um cenário cada vez mais digital e com a popularização da inteligência artificial, seja entrando nas casas por meio dos assistentes virtuais ou representando as marcas em conversas com chatbots e embaixadores virtuais, é de extrema importância que as marcas cuidem para que esses canais e interações também representem a marca e o cuidado com o cliente. Usando tecnologias que simulem as interações humanas, é possível criar uma conexão emocional com as "máquinas", tornando-as aliadas no processo de encantamento de clientes. Ficou claro que trabalhar a conexão emocional ao longo caminho do consumidor pode levá-lo à defesa de marca, sendo esta a nova definição de fidelização, mostrando a relação entre a conexão emocional e a fidelização de clientes.

A segunda parte da pesquisa se deu por meio de questionário online para obter dados estatísticos que fossem comparados ao referencial teórico, com o objetivo de avaliar a eficácia do marketing emocional como estratégia de fidelização (objetivo geral da pesquisa) trabalhando os resultados da pesquisa de campo no Capítulo 3.

Com a análise dos dados obtidos, por meio dos três fatores mais citados como responsáveis pela conexão emocional com a marca (memória afetiva, campanhas com histórias marcantes e atendimento), podemos constatar que tanto as estratégias de atração quanto de venda e pós-venda são importantes para estreitar o relacionamento com os clientes, envolvendo os diversos setores da empresa na estratégia.

Os clientes com conexão emocional demonstraram ser menos sensíveis a preço quando comparados aos consumidores que afirmam não ter esse vínculo. Respondentes que possuem 
conexão com a marca também apresentaram maior tendência a falar bem da marca para amigos, familiares ou em Redes Sociais, validando a relação de conexão emocional com o conceito de fidelidade defendido por Kotler, Kartajaya e Setywan (2017). Ainda, os consumidores com conexão emocional apresentaram maior predisposição para comprar novos produtos lançados por sua marca preferida. Os registros trazem que consumidores que afirmam ter vínculo com a marca preferida apresentam maior tendência a se manterem fiéis a marca, validando a hipótese apresentada na introdução desta pesquisa.

Correlacionando os conceitos de marketing emocional e fidelização de clientes baseados no referencial teórico e analisando os resultados da pesquisa de campo, podemos concluir que o marketing emocional é uma estratégia eficaz para a fidelização de clientes, que poderá ser comprovada por meio de fatores como: menor sensibilidade a preço, maior propensão a recompra e/ou a aquisição de novos produtos da marca, e por meio de uma atitude de defesa e divulgação de forma espontânea.

\section{REFERÊNCIAS}

BENNEMANN, Lina. Marketing 4.0: o que é e como praticar. Comunidade Sebrae, c2019. Disponível em: <https://comunidadesebrae.com.br/blog/marketing-4-0-o-que-e-e-comopraticar/>. Acesso em: 24 maio 2020.

KOTLER, P., KARTAJAYA, H., SETIWAN, I. Marketing 4.0: do tradicional ao digital. Rio de Janeiro: Sextante, 2017.

KOTLER, Philip. Administração de marketing / Philip Kotler, Kevin Lane Keller; tradução Sônia Midori Yamamoto; revisão técnica Edson Crescitelli. - 14. ed. - São Paulo: Pearson Education do Brasil, 2012.

MARQUES, FABIO. Guia prático da excelência em serviços: como conquistar clientes, aumentar os lucros e viver melhor! São Paulo: Nobel, 2006.

REDAÇÃO NUBANK. Prêmios de atendimento ao cliente que o Nubank já recebeu. Blog Nubank, 2019. Disponível em: <https://blog.nubank.com.br/nubank-atendimento-clientepremios/> Acesso em: 01 de maio de 2020

ROBINETTE, Scott. BRAND, Claire. LENZ, Vicki. Marketing Emocional: A Maneira Hallmark De Ganhar Clientes Para Toda A Vida. São Paulo: Makron Books, 2002.

SALZMAN, Marian. Why Emotional Branding Will Always Give Us Paws For Thought. Forbes, 2019.2 Disponível em: $<$ https://www.forbes.com/sites/mariansalzman/2019/08/03/why-emotional-branding-willalways-give-us-paws-for-thought/amp/>. Acesso em: 17 maio. 2020.

TOMSETT, Danny. Emotional Connection:2020's Biggest CX Trend. Forbes, 2020. Disponível em: <https://www.forbes.com/sites/forbestechcouncil/2020/02/28/emotionalconnection-2020s-biggest-cx-trend/amp/> . Acesso em: 17 maio 2020. 